\title{
Inactivation of Oral Cancer Cell Using Active Species Generated by Atmospheric Plasma
}

\author{
Reoto Ono, Tetsuya Ohtsubo, Nobuya Hayashi, Reona Aijima*, \\ Yoshio Yamashita*, and Masaaki Goto* \\ Interdisciplinary Graduate School of Engineering Sciences, Kyushu University \\ 6-1 Kasuga-koen, Kasuga-shi, Fukuoka 816-8580, Japan \\ * Faculty of Medicine, Saga University \\ 5-1-1 Nabeshima, Saga-shi, Saga 849-8501, Japan
}

Keywords: Dielectric barrier discharge, Active species, Oral cancer cell, HSC2, Inactivation

\section{Introduction}

Recently, studies on inactivation of cancer cells using plasmas have been reported [1-3]. Active species such as $\mathrm{O}_{3}$ and $\mathrm{NO}_{x}$ can be generated by atmospheric plasmas. Cancer cells are irradiated by plasmas through medium in several studies $[4,5]$. However, some cancer cells are generated on the surface of organs and skin. A method that cancer cells are irradiated by plasmas through medium cannot apply to all cancer cells treatment. Thus, a method that cancer cells removed medium are irradiated by plasmas is necessary for cancer cells treatment using plasmas. One of medical fields that the method can apply would be oral surgery. Oral cancer cells are exposed to air unlike cancer cells on organs. Cancer cells would be weak to the oxidizability compared with normal cells. The effect of the method that cancer cells removed medium are irradiated by plasmas on the inactivation of oral cancer cells is expected to be high compared with the method that cancer cells are irradiated by plasmas through medium. In this study, Dielectric Barrier Discharge (DBD), one of the discharge type that occurs atmospheric plasmas, was used, and the different of inactivation effect of oral cancer cells with very small amount of medium or through medium using DBD was evaluated.

\section{Experimental setup}

Figure 1 shows the schematic of DBD device. A cylindrical ceramic tube that had the length of 130 $\mathrm{mm}$ and the inner diameter of $4 \mathrm{~mm}$ was covered

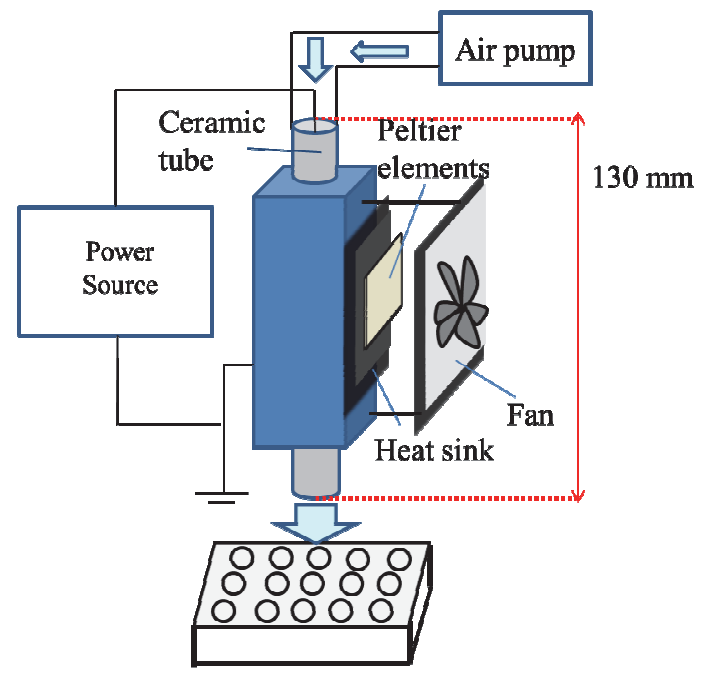

Fig. 1. Schematic of DBD device.

with a rectangular electrode. Also, a stainless mesh was attached along the inner wall of the ceramic tube. The stainless mesh was connected to a high voltage power source, and the rectangular electrode was connected to the ground. The electrode was attached a heat sink, peltier elements and a fan in order to cool heat generated by the discharge around the electrode. Air gas was supplied by an air pump and silicon tube. DBD occurred by applying $\mathrm{AC}$ voltage of several $\mathrm{kV}$, and active species such as $\mathrm{O}_{3}$ and $\mathrm{NO}_{2}$ were generated. The distance between the tip of the ceramic tube and oral cancer cells was approximately $12-13 \mathrm{~mm}$. HSC2 was used as a sample cell line. HSC2 is squamous cell carcinoma and has shape like cuboidal [6,7]. Sample number was 3 or 4 . 
2.1. Irradiation to HSC2 with very small amount of medium.

Medium ( $\alpha$-mem) that cultivates HSC2 was removed by an electric pipette from 96-well microplate and these cells were irradiated by active species generated by DBD. After irradiation, medium was dropped into the microplate, and $\mathrm{HSC} 2$ was cultivated in $\mathrm{CO}_{2}$ incubator at $37{ }^{\circ} \mathrm{C}$. The number of cells was evaluated by an absorbance of the medium at the wavelength of $450 \mathrm{~nm}$ after $24 \mathrm{~h}$ cultivation.

\subsection{Irradiation to $\mathrm{HSC} 2$ through medium.}

HSC2 was irradiated by active species generated by $\mathrm{DBD}$ through medium of $100 \mu \mathrm{L}$. After irradiation, the medium was replaced to new medium. $\mathrm{HSC} 2$ was cultivated in $\mathrm{CO}_{2}$ incubator at $37{ }^{\circ} \mathrm{C}$. The number of cells was evaluated by an absorbance of the medium at the wavelength of $450 \mathrm{~nm}$ after $24 \mathrm{~h}$ cultivation.

\section{Results and discussion}

Figure 2 shows the relative number of $\mathrm{HSC} 2$ irradiated active species generated by DBD varying irradiation period. Values of each condition in Fig. 2 are normalized by that of control (Without irradiation). HSC2 irradiated by active species for $10 \mathrm{sec}$ with very small amount of medium decreased to approximately $4 \%$ of the control number. However, the number of HSC2 decreased to approximately only $75 \%$ of the control number as cells with very small amount of medium were irradiated by gas only for $10 \mathrm{sec}$. This result indicates that the inactivation of HSC2 irradiated by active species with very small amount of medium would be not caused by the drying.

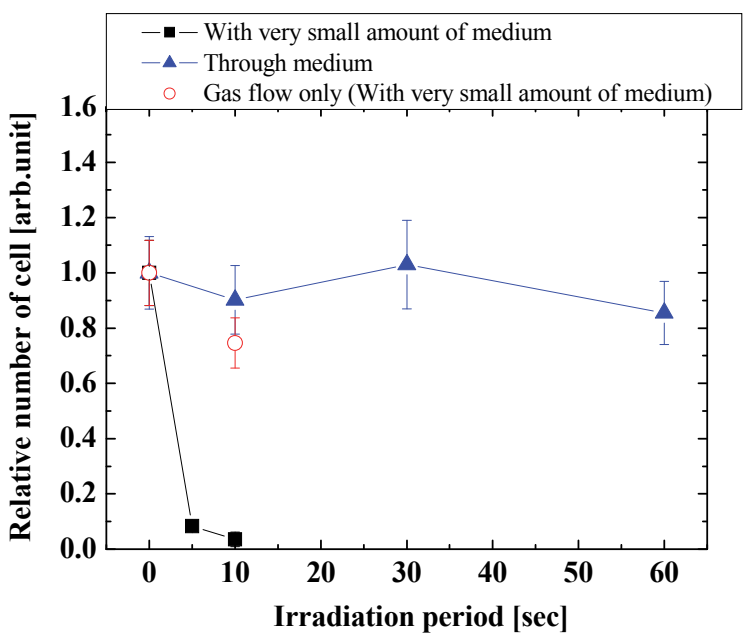

Fig. 2. Inactivation effect of HSC2 irradiated by active species generated by DBD with very small amount of medium or through medium.

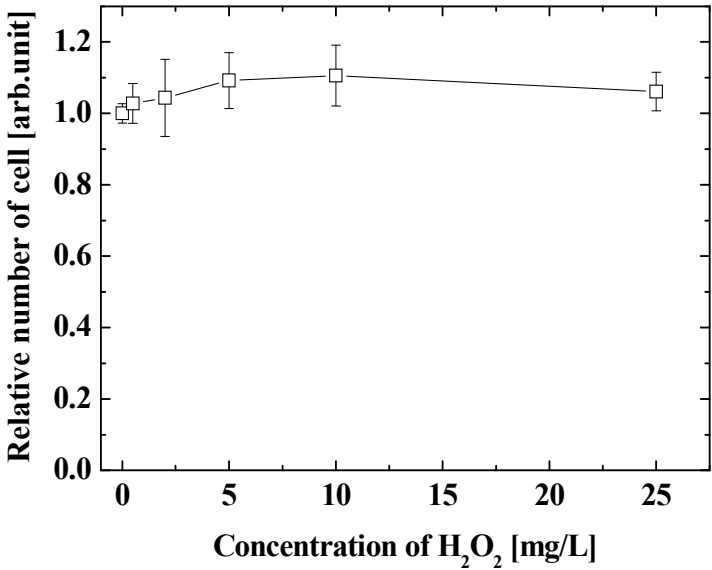

Fig. 3. Inactivation effect of $\mathrm{HSC} 2$ in medium varying concentration of $\mathrm{H}_{2} \mathrm{O}_{2}$.

Furthermore, the number of HSC2 irradiated by active species for $60 \mathrm{sec}$ through medium decreased to approximately only $85 \%$ of the control number. HSC2 with very small amount of medium would be inactivated by active species in the gas phase and in very small amount of medium. Therefore, the inactivation effect of HSC2 irradiated by active species with very small amount of medium would be high compared with that through medium.

Active species in medium irradiated by DBD were generated. One of active species in medium irradiated by DBD was $\mathrm{H}_{2} \mathrm{O}_{2}$, which is confirmed by a test paper. Figure 3 shows the relative number of $\mathrm{HSC} 2$ varying the concentration of $\mathrm{H}_{2} \mathrm{O}_{2}$ in medium. The concentration of $\mathrm{H}_{2} \mathrm{O}_{2}$ in medium was varied with pharmaceutical products, and HSC2 was exposed in the medium of $100 \mu \mathrm{L}$ for $90 \mathrm{sec}$. Values of each condition in Fig. 3 are normalized by that of control (Without irradiation). From Fig.3, $\mathrm{HSC} 2$ exposed in medium that include $\mathrm{H}_{2} \mathrm{O}_{2}$ of the concentration of $1-25 \mathrm{mg} / \mathrm{L}$ was not inactivated. Also, the concentration of $\mathrm{H}_{2} \mathrm{O}_{2}$ in medium irradiated by active species generated by DBD for 90 and $180 \mathrm{sec}$ was approximately 2 and $8 \mathrm{mg} / \mathrm{L}$, respectively. Based on these results, $\mathrm{H}_{2} \mathrm{O}_{2}$ would not be active species that inactivate $\mathrm{HSC} 2$. Active species such as $\mathrm{NO}_{2}{ }^{-}$and $\mathrm{NO}_{3}{ }^{-}$in medium irradiated by DBD were generated, which was confirmed by a test paper. The concentration of $\mathrm{NO}_{2}{ }^{-}$and $\mathrm{NO}_{3}{ }^{-}$in medium irradiated by DBD was over 60 and 500 $\mathrm{mg} / \mathrm{L}$, respectively. $\mathrm{NO}_{\mathrm{x}}$ may be main active species that inactivate $\mathrm{HSC} 2$.

\section{References}

1. G. Fridman, A. Shereshevsky, M. M. Jost, A. D. Brooks, A. Fridman, A. Gutsol, V. Vasilets and G. Friedman, Plasma Chem. Plasma Process, 
27 (2007) 163.

2. H. Tanaka, M. Mizuno, K. Ishikawa, K. Nakamura, H. Kajiyama, H. Kano, F. Kikkawa and M. Hori, Plasma Med., 1 (2011) 265.

3. J. Huang, H. Li, W. Chen, G. H. Lv, X. Q. Wang, G. P. Zhang, K. Ostrikov, P. Y. Wang and S. Z. Yang, Appl. Phys. Lett., 99 (2011) 253701 .

4. S. J. Kim, T. H. Chung, S. H. Bae and S. H. Leem, Appl. Phys. Lett., 97 (2010) 023702.
5. X. Yan, Z. Xiong, F. Zou, S. Zhao, X. Lu, G. Yang, G. He and K. Ostrikov, Plasma Process Polym., 9 (2012) 59.

6. F. Momose, T. Araida, A. Negishi, H. Ichijo, S. Shioda and S. Sasaki, J. Oral Pathol. Med., 18 (1989) 391.

7. M. Ikuta, K. A. Podyma, K. Maruyama, S. Enomoto and M. Yanagishita, Oral Oncol., 37 (2001) 177. 